\title{
Comment on: Ferrannini. Learning From Glycosuria. Diabetes 2011;60:695-696
}

\author{
Robert C. Stanton
}

$\mathbf{I}$

$\mathrm{n}$ the March issue of Diabetes, there is a very interesting article by Jurczak et al. (1) about glucose homeostasis and $\beta$-cell function in mice with a deletion in SGLT-2. There is also an accompanying editorial by Ferrannini (2) that is appropriately laudatory to the article but there are some extraordinary comments including, "Collectively, these findings prove that reduced SGLT-2 activity-whether genetically or experimentally induced-is efficacious and relatively safe ...." All of us are entitled to our opinion. But the combined knowledge obtained from humans with renal glycosuria, the clinical trials with these drugs, and this transgenic mouse study are important and intriguing but do not prove long-term safety, especially in diabetic patients with kidney disease.

There are no safety studies in diabetic patients with kidney disease. And there is certainly reason for concern that patients with kidney disease (at any stage) may have deleterious consequences being exposed to high glucose levels in the renal tubules for years. Thus I have major safety concerns about the long-term use of these new medications in patients with diabetic kidney disease. At the very least the risks to patients with diabetic kidney disease are unknown.
More concerning was the statement at the end of the editorial that "No potential conflicts of interest relevant to this article were reported." A quick online search revealed that Dr. Ferrannini is the first author on a study using an SGLT-2 inhibitor. This study was sponsored by the drug company. Indeed, it is reference number 13 in the editorial. In addition, there is an abstract in which Dr. Ferrannini is the first author in which another drug company's SGLT-2 inhibitor is studied.

I have no problem at all with researchers expressing their thoughts, ideas, and opinions, but it is extremely important that potential conflicts be clearly stated.

\section{ACKNOWLEDGMENTS}

No potential conflicts of interest relevant to this article were reported.

\section{REFERENCES}

1. Jurczak MJ, Lee H-Y, Birkenfeld AL, et al. SGLT2 deletion improves glucose homeostasis and preserves pancreatic $\beta$-cell function. Diabetes 2011;60: 890-898

2. Ferrannini E. Learning from glycosuria. Diabetes 2011;60:695-696
From the Joslin Diabetes Center, Boston, Massachusetts.

Corresponding author: Robert C. Stanton, robert.stanton@joslin.harvard.edu. DOI: $10.2337 / \mathrm{db} 11-0483$

(C) 2011 by the American Diabetes Association. Readers may use this article as long as the work is properly cited, the use is educational and not for profit, and the work is not altered. See http://creativecommons.org/licenses/by -nc-nd/3.0/ for details. 